\title{
DEVELOPING GRAVITY MODEL FOR AIRLINE REGIONAL ROUTE MODELLING
}

\author{
Allan NÕMMIK ${ }^{1,2}$, Sven KUKEMELK ${ }^{3,4}$ \\ ${ }^{1}$ Estonian Aviation Academy, Lennu 40, Reola, Ülenurme Parish, Tartu County 61707, Estonia \\ ${ }^{2}$ Tallinn University of Technology, Department of Logistics, Akadeemia tee 15A, Tallinn, 12618, Estonia \\ ${ }^{3}$ Nordic Aviation Group, Sepise 1, Tallinn,11415, Estonia \\ ${ }^{4}$ Tallinn University of Technology, Department of Economics and Business Administration, \\ Akadeemia tee 3, Tallinn, 12618, Estonia \\ E-mails: allan.nommik@eava.ee (corresponding author); sven.kukemelk@nagroup.ee
}

Received 02 June 2015; accepted 02 March 2016

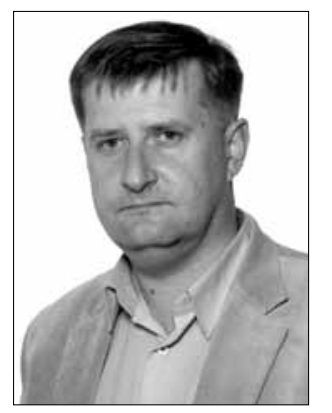

\section{Allan NÕMMIK}

Education: Tartu Aviation College (2000), University of Tartu (2003), Tallinn University of Technology, PhD studies (since 2013).

Experience: 15 years of experience in higher education, including applied research. Present position: lecturer at Estonian Aviation Academy.

Research interests: economics and geography of air transportation, civil engineering.

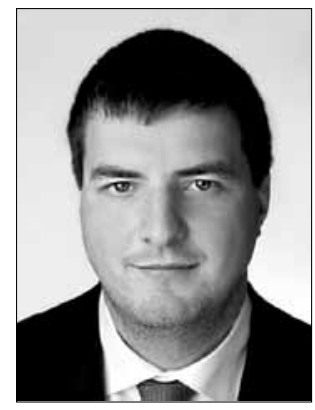

\section{Sven KUKEMELK}

Education: Estonian Aviation Academy (2010), Vilnius Gediminas Technological

University (2012), Tallinn University of Technology, PhD studies (since 2013)

Experience: 6 years of experience in network planning and aviation business analysing. Present position: Executive Director Business Development at Nordic Aviation Group.

Research interests: network planning, fleet development, commercial management.

Abstract: the gravity model is a method that is used by transportation researchers, airline network planners and analysts to explain how traffic is distributed between city pairs in correlation to the distance or travelling time between them, which as a result indicates the behaviour of travellers or the performance of the transport connection. However, the applicability of the model depends on the reliability of the results, which poses a major issue for researches. The major difficulty is to obtain comparable qualitative insights into the key parameters that are selected. This paper presents a possibility study for the use of the gravity model for regional route planning from the scientific point of view and suggests possibilities of gravity model calibration for airline network analysis including alternative methods for estimating the gravity potential of destinations and measurement of the influence of distance on the potential. The focus of the research is the ability to explain and forecast the development of regional air transportation routes in the commercial aviation network when there is a lack of recorded booking demand data.

Keywords: air transportation route planning, gravity model, regional aviation.

\section{Introduction}

The gravity model or law gets its name from physics; it is referred to as the modified law of gravitation. Gravity equations have a long history of use in social sciences for transportation planning, describing and forecasting the movement of people, goods and services (Truscott, Ferguson 2012). One of the implication areas, developed 
in the second part of the 20th century, is the use of the model in transport geography for assessing and predicting the total number of trips for the whole population. For example the time-geographic concept of Torsten Hägerstrand which consists of the gravity model "relate to how and why individuals, in one or more populations, link to each other and move (or are moved) between places which are the cornerstones of transport research" (Ellegård, Svedin 2012). Various sources define the gravity like effect of spatial interaction differently; however, they model it similarly. There are some differences in formulas and approaches towards the research depending on the task, the researcher's background and area of research (Ellis, van Doren 1966; O’Kelly 1983; Weber, Sen 1985).

"As the aviation market is an industry which in 2008 had a 425 billion USD direct annual revenue and an indirect 1540 billion USD annual impact" (Gossard 2011), it is fair to call aviation a mature industry. As in every well-developed field there are numerous methodologies and tools developed to simplify processes and ensure the best financial outcome.

\section{Practical uses of the gravity model in network planning}

Due to high expenses and the dynamic nature of the aviation market, regional airlines need some instruments which could be based on a certain methodology. According to the classical theory, the market should be segmented into three main categories: business trips, leisure trips and trips for visiting friends or relatives. The demand is dependent on the population, the size of salaries, the structure of economy and historical or demographical factors, etc. The key criteria for planning for a pre-defined region would be the assessment of the current services at destination $j$ and comparison of their correspondence to the real needs of destination $i$.

In the last 10 years all over Europe it has been observed that passengers do not always choose the closest airport for their travel but rather an airport where the costs of services are lower, which could have be triggered by low cost carriers. In aviation that is called surface leakage, and just for that reason the gravity model is needed in modern network planning, it can be used to understand what would be the potential provided that similar services would be available to the customer at the nearest airport.

Business traffic is mostly driven by the number of frequencies offered for a place as businessmen have a tight schedule, and cold therefore make the best use of their time, whereas leisure travellers are driven by the number of seats offered - more seats mean a lower cost as they are price sensitive.

In all mature markets like Western-Europe or North-America, it is not so challenging to understand the demand between bigger city pairs as they might be dominated by a certain group and have been served with the same capacity for the last 10-20 years (Maertens 2011). However, developments can be challenging to new markets (no previous operations) due to having not sufficient data about the market size, demand segmentation, seasonality and schedule preferences.

One way out could be the use of some classical approach involving a market survey. However, it has been found that in the case of airline route planning the surveys do not give a realistic picture due to the difficulty of gaining access to the target group since respondents are not responsible for taking actual commitments. Changes in the operational environment also affect research models and methodology, as the results of the carefully completed surveys cannot be fully implemented. The factors that influence the results significantly are:

- changes in the market situation, like joint-ventures, code-share agreements or special prorate agreements;

- changes in the function of passenger's willingness to pay due to previous experience with low cost or high level airline services; changes in traveller's real income; society's trends for travelling behaviour;

- changes in politics, like a state joining some political or economic union or decisions for preference of or development of some transportation mode.

Philosophically, in transportation, the movement of people in space can be defined as the direct implementation of a material connection or the material connection process between settlements (Mereste, Nymmik 1984). For social sciences different forms of gravity models are very common as the amount of related data is easier to access (Paas 2000). A pre-defined collection of data could be used for example in the assessment of economic systems or for explaining traffic development using different factors, such as attractions at the origin and destination cities in addition to the distance effect (Jin et al. 2004). Route planning is one of the key pre-requisites for successful airline operations; therefore, the gravity mod$\mathrm{el}$ is one of the methodologies that network planners use for forecasting:

- demand of new routes which could be started;

- possibilities of increasing the capacity of existing routes;

- development of existing routes due to market changes.

In recent years, the gravity module has seen surge a in its applicability due to the rapid pace of development in the information technology sector which directly influences the commercial distribution process of airlines (Bilegan et al. 2007). Conventional methods include the 
use of historic data on booking trends called the MIDT (Marketing Information Data Tapes) and an overview of the number of sales through the IATA revenue sharing scheme (Kukemelk 2012), which in general demonstrates the different methods for obtaining the number of passengers travelling between certain cities. However, getting access to such systems is costly for regional airlines and airports due to a high investment cost and the limiting factor that they only provide qualitative insights into the past behaviour whilst not taking into account future trends or implications for areas where there have been constraints. Regional and peripheral airports where passengers use more than one transfer station are especially problematic, as the accuracy of the systems to predict multi-stop journeys is relatively low, hence distorting true market sizes and reducing the attractiveness of a regional airport in the eyes of potential newcomers (Kukemelk 2014). If it is believed that a destination has peripheral characteristics then the gravity module is amongst the more preferred options for revealing the true potential of the destination for all possible airlines.

For analysing or forecasting the flows of travellers $F$ or planning the transport capacity for serving them, the model takes into account the combination of the population sizes and the underlying distance between them (Eq. (1)).

$$
F_{i j}=k \frac{P_{i}^{\alpha} P_{j}^{\lambda}}{R_{i j}^{\beta}},
$$

where the constants are as follows:

$P_{i}$ and $P_{j}$ - importance of the location of origin and the location of destination;

$R_{\mathrm{ij}}$ - distance between the location of origin and then the location of destination;

$k$ - a proportionality constant;

$\alpha$ (alpha), $\beta$ (beta), $\lambda$ (lambda) - empirical constants.

Before the gravity model can be used for the prediction of current travel demand, it must be calibrated. The calibration has to take into account the operational environment dependent on geo-economic factors or factors that fall outside the control of airlines and service dependent factors (Srinidhi 2010) which may not be truly independent components of the airline product.

The calibration consists of finding the value of each empirical constant of the model to ensure that the estimated results are similar to the observed flows. If it is not the case, the model is almost useless, as predictions have no value without context. It is impossible to know if the process of calibration is accurate without comparing the estimated results with empirical evidence (Kukemelk 2012). From this point of view, some researchers have offered a solution for calibrating, by indicating that the empirical parameters $\alpha, \beta, \lambda$ should describe (Rodriguez et al. 2009): $\beta$ - transport friction related to the efficiency of the transport system between two locations; for airlines this could be described by either offer or production.

$\lambda$ (lambda) - potential to generate movements. For movements of people, lambda is often related to an overall level of welfare. Lambda could also be described by the GDP per capita levels.

$\alpha$ (alpha) - potential to attract movements (attractiveness), related to the nature of economic activities at the destination. It should be a combination of attractiveness and accessibility. It can also be partly described by the number of UNESCO World Heritage sites in the area or the number of tourist nights spent per fixed period.

Passengers are not rational and do not make decisions based on ceteris paribus. Usually models in social sciences imply that customers behave rationally. It is assumed that they have all the information on the services offered. Every passenger who has to choose faces a dilemma: to buy the cheapest product or the one caters best for the client's needs.

The main tools used today for new route planning collect historical market data and based on that try to simulate what would be the most likely outcome of a new flight or frequency. This data, however, does not include a complete data set any more, as the booking figures of low fare carriers (LFC) are just an estimation due to noncompliance with traditional carriers' rules of reporting. To come up with better quality data and ensure sustainable development, network planners are looking into alternative methods. One of the methods looked at is the gravity module with its various implications.

One additional field of attention is the application of external factors such as wars, unrest and terror. For example, people who would usually take their winter vacations in Egypt will change their preference due to elevated terror threats and reduced offers of airlines. However, once the crisis is over and people could go back for holiday, the companies tend not to offer these destinations (at least in the beginning) as they have no previously recorded data. Whereas passengers who spent the holidays somewhere else, for example in the Canary Islands, which is the main alternative resort for winter getaways from Europe, might start looking back to the Egyptian market, which triggers an illogical decline of demand in the Spanish market. The same reasoning could be applied when analysing the spent attractiveness of one city to the passengers another city. Attractiveness can also be one sided - meaning that people only visit one place and there is no both way traffic.

From the point of view of humanism, it is impossible to study human behaviour with methods coming from natural sciences. Traffic forecasting has to take into account the objective of a passenger's trip, individual value judgment, inclinations and preferences. Predicting 
people's decisions is of upmost challenge and might not be possible through models at all.

Offers which are provided for customers by airlines involving transfers at hubs might not always be reasonable for passengers due to the travel costs or travel time. Some alternatives, like using a combination of air transport and other modes of transportation could be preferred. Additionally, passengers plan their trips themselves and may use a combination of several LFCs flights. As a result, passengers travelling from one airport to another do not necessarily just travel between the operated city-pair or municipalities located in the immediate vicinity of the airports. From the point of view of the gravity model for airline network analyses, the attractiveness of the cities is not expedient. That means that the air transportation network is being viewed like a phenomenon in its own right, which is often not associated with the local population density or local economy.

Redrafting Bertrand Russell's (Russel 1994) opinion about the relativity theory of Einstein, it could be stated similarly that the more accurately researchers determine the profile of a passenger the less accurate is the production which passengers are offered; the more accurately we determine the preferred destinations, the less accurate will be the profile of passengers.

\section{Development of the gravity model to highlight the implications of the market}

The choice of airport is mostly influenced by the airport's attraction, but resistance of distance could be measured by both kilometres and time (Legeza et al. 2010). However, distance can also be substituted with the travel time as the key parameter for making a choice. Airports' attraction could be measured by the number of passengers served by the airport (Nõmmik 2003).

The airline pricing policy is effectively developed based on the competition in the market. Airlines which cater for the needs of the business sector have to offer high frequency services; therefore, they tend to have smaller aircraft and lower load factors. As a result, this increases the airlines' need for higher revenue. Whereas, low fare airlines tend to fly bigger aircraft more seldom and, as such, have lower production costs, which results in the ability to provide lower fare levels and, through reduction of fares, the ability to stimulate extra demand.

For our research, traffic from Tallinn airport during 2013 and 2014 was used. Tallinn Airport was chosen as a good example of a regional airport in the European Union as it is a member airport in the European Union Transportation Commissioner's Aviation Platform (European Commission) 2010. In order to minimize the effects of temporary demand fluctuations, the discount data was analysed annually.
Table 1. Traffic data according to destinations for 2013 and 2014.

\begin{tabular}{lll}
\hline \multicolumn{1}{c}{ Airport } & Passengers 2013 & Passengers 2014 \\
\hline Frankfurt Main & $58,036,948$ & $59,566,132$ \\
\hline Amsterdam Schiphol & $52,569,250$ & $54,978,023$ \\
\hline Moscow Sheremetyevo & $30,765,078$ & $31,567,974$ \\
\hline Copenhagen & $24,029,205$ & $25,590,674$ \\
\hline Oslo Gardemoen & $22,955,723$ & $24,068,955$ \\
\hline Stockholm Arlanda & $20,706,411$ & $22,462,028$ \\
\hline Brussels & $19,105,398$ & $21,904,723$ \\
\hline Helsinki & $15,272,573$ & $15,943,276$ \\
\hline Warsaw Chopin & $10,683,706$ & $10,590,473$ \\
\hline Kiev Borispol & $7,926,964$ & $6,890,443$ \\
\hline Riga & $4,793,045$ & $4,813,959$ \\
\hline
\end{tabular}

The criteria for choosing the analysed destination airports (Airport Council International 2014, 2015) for the study, provided in Table 1, were:

- regularity of servicing the routes served during the year at least 4 times per week to highlight only the core routes which have significant implications on the true air service demand of the airport;

- international routes to the hub-airports not longer than the Great circle distance, $1852 \mathrm{~km}$ $(1000 \mathrm{~nm})$, or short haul routes which could be accepted like regional flights, or block-time of a route not longer than $2 \mathrm{~h} 30 \mathrm{~m}$ (Tallinn airport. Timetable. 2014;

- routes which have been served for at least two years in a row to highlight the potential they have obtained;

- destinations served only by low cost carriers were excluded to avoid specific gradients of movement based on the significantly low prices.

For the calculation of the gravity effect of every destination in Tallinn airport (Tallinn Airport. Timetable 2014; Tallinn Airport 2015), Equation (2) was used, where $P_{i}$ indicates the airport and $i$ - attraction, measured by the passengers served by the airport. For the calibration of the model, data of 2013 and random combinations of $k$, $\alpha$ and $\beta$ were used until one which has a minimal $P_{n}^{m}$, deviation was found (Eq. (3)).

$$
\begin{aligned}
F_{i} & =k \frac{P_{i}^{\alpha}}{R_{i j}^{\beta}}, \\
\Delta_{F} & =\frac{\sqrt{\sum_{i=1}^{n}\left(f_{i}-F_{i}\right)^{2}}}{n-1},
\end{aligned}
$$

where: $n$ - number of destinations, $f$ - real market share of the route for destination $i, F-$ theoretical market share for destination $i$. 
For testing the adaptability of the gravity model, passenger flows to the destinations were forecast using the Spearman rank Equation (4).

$$
r_{s}=1-\frac{6 \sum_{i=1}^{n} d_{i}^{2}}{n\left(n^{2}-1\right)},
$$

where: $r_{s}$ - the coefficient of the correlation, $d_{i}-$ the difference between the rank of $f$ and $F$ for the observation of $i$. During testing we found that the difference between the theoretical and real rank for Riga airport was very high. Therefore, two separate analyses were conducted: one with Riga airport $\left(r_{s R}\right)$ included and one without Riga airport $\left(r_{s O}\right)$.

Table 2. Correlation of real and calculated market shares

\begin{tabular}{llccc}
\hline & $\begin{array}{c}\text { Great circle distance } \\
(\mathrm{km})\end{array}$ & \multicolumn{2}{c}{$\begin{array}{c}\text { Block time } \\
(\mathrm{min})\end{array}$} \\
\hline Year & $r_{s R}$ & $r_{s O}$ & $r_{s R}$ & $r_{s O}$ \\
\hline Traffic in 2013 & 0.54 & 0.75 & 0.55 & 0.76 \\
\hline Traffic in 2014 & 0.55 & 0.75 & 0.56 & 0.76 \\
\hline
\end{tabular}

The calculation results can be seen in Table 2. When assessing the relevance of block-time versus range, the analysis revealed that using the distance in kilometres for the calculation of the influence on range resulted in approximately the same results as the usage of block-time for traffic without Riga airport.

\section{Discussion and conclusions}

A conscious application of the laws of science allows the adjustment of both empirical and theoretical knowledge of the process of cognition (Nymmik 1981). From the point of view of transport planning, we have to create models which would be able to project these subjective choices. This is also the key goal of the article - an effort to try to model the behaviour and reasoning of individuals who do not follow exact rulings. Such research is faced with a lot of uncertainties, like measurement of freedom in travel time or choice of numbered destinations. Travelling could be understood as a human right or as a legal privilege.

The very high difference between the theoretical and real rank of Riga airport could be explained by the specific role of this airport in the air transportation network of the Baltic States in the time period analysed. The objective reason here could be the fact that the Baltic market is relatively small and is suffering from a lack of connectivity, and, as the main carrier in Riga airport has pre-defined all Baltic States as its home market, it is natural that there will be extended sales efforts to ensure high market penetration. However, such active sales and marketing activities cannot be taken into account in the model and have to be calibrated later based on the actual demand and supply ratio.
The applications allow to project theoretically the demand between any two points on the planet; however, calibrating the results for the whole world would be so time consuming that once they were ready the model (as data gets old) would not be applicable anymore. Passengers are not completely free in choosing the way, time and mode of travelling and no airline would ever be able to provide an offer for everyone according to their exact needs. This is especially true for regional or peripheral airports where the demand is quite often dictated by supply. The analysis showed the adaptability of the gravity model for regional route planning where the role of potential is played not by the population size but the number of passengers served at destination airports.

This research focuses on the application of the gravity model for all passengers who actually need to use air services. To solve this problem, the determination or description of the passenger is not a priority. The number of the passengers served at the $j$ airport characterizes the potential of the airport as a final destination and the potential for transfer traffic as well. It will be assumed that the system of gravity relations between airports has extensive characteristics and covers all airports around the world. If it is needed, the potential for transfer traffic could be calculated separately taking into account the transfer traffic or traffic of some airlines operated at $j$ airport.

In general, after a careful examination of different models, including the gravity model, it is clear that theory cannot provide complete explanations which could be acceptable for research focused on passengers' behaviour yet. Additionally, it is impossible to evaluate the stimulation effect of market growth which would be generated by a new air route. From the point of view of the airline, it is difficult to obtain a realistic picture of the market using a survey.

The gravity model shown in this paper does not take into account the knowledge about passengers' profiles. Researchers agree that the information about every passenger's preferences is important, but such a level of sophistication could be considered once positive results are observed for the applications of the current study of gravity module implications. Two approaches like "contemporary positivism and humanism are motivated by parallel ideals of enlightenment-through-science, by a concern with reliable social knowledge as the basis for rational public policies" (Tibbetts 1982). From this point of view, a highly accurate determination of the profile of demand is not an only-begotten approach for forecasting the demand of a route.

In this paper, we have shown that the calibrated gravity model, based on the presented approach, could be an efficient and simple tool for an airline's route planning dependent on service factors. For preparing the 
forecast of demand for some routes, the planners will have to take into account the already existing forecasts for airports prepared by airport's authorities without having to conduct their own time-consuming and often costly databases. The gravity model gives a primary answer which does not exclude additional market research with the purpose of finding out the passenger's' profile in general and by routes. The goal of this research would be to improve of revenue management processes and service concept to ensure the achievement of the forecasted demand for air transportation routes.

\section{References}

Airport Council International. 2014. ACI EUROPE Airport Traffic Report, December 2013, Q4 2013 and Full Year 2013.

Airport Council International. 2015. ACI EUROPE Airport Traffic Report, December 2014, Q4 2014 and Full Year 2014.

Bilegan, I. C.; Cosenza, C. A. N.; Gonzalez-Rojo, S., et al. 2007. A maximum entropy approach to update airlines demand distributions, Inverse problems in Science and Engineering 15(1): 19-29. http://dx.doi.org/10.1080/17415970600573825

Ellegård, K.; Svedin, U. 2012. Torsten Hägerstrand's timegeography as the cradle of the activity approach in transport geography, Journal of Transport Geography 23: 17-25. http://dx.doi.org/10.1016/j.jtrangeo.2012.03.023

Ellis, J. B.; Van Doren, C. S. 1966. A comparative evaluation of gravity and system theory models for statewide recreational traffic flows, Journal of Regional Science 6(2): 57-70. http://dx.doi.org/10.1111/j.1467-9787.1966.tb01316.x

European Commission. 2010. New Aviation Platform to address challenges for the European aviation sector, Brussels [online], [cited 30 May 2015]. Available from Internet: http:// europa.eu/rapid/press-release_IP-10-1354_en.htm.

Jin, F.; Wang, F.; Liu, Y. 2004. Geographic patterns of air passenger transport in China 1980-1998: imprints of economic growth, regional inequality, and network development, The Professional Geographer. AAG: Association of American Geographers 56(4): 471-487.

Gossard, P. 2011. How to finance fleet plans, in Airbus fleet planning seminar, 7-11 November 2011, Toulouse, France.

Kukemelk, S. 2012. Use of gravity model: Master's thesis. Vilnius Gediminas Technical University, Vilnius, Lithuania.

Kukemelk, S. 2014. Changes in regional airport landscapes will affect all parties involved and steps should be taken to cope with the new reality, Journal of Airport Management 8(4): 334-342.

Legeza, E.; Selymes, P.; Torok, A. 2010. Investigation of European air transport traffic by Utility Based Decision Model, Aviation 14(3): 90-94. http://dx.doi.org/10.3846/aviation.2010.14

Maertens, S. 2011. Estimating the market power of airports in their catchment areas - a Europe-wide approach, Journal of Transport Geography 22: 10-18. http://dx.doi.org/10.1016/j.jtrangeo.2011.11.007

Mereste, U. I.; Nymmik, S. J. 1984. Sovremennaja geografija: Voprosy teorii. Moskva: Mysl' (in Russian).

Nymmik, S. J. 1981. Prostranstvennye zakony obščestva $i$ social'no-ekonomičeskaja geografija. Metodologija i metody izučenija social'no-ekonomičeskih territorial'nyh sistem. Tartu: TRU, 16-31 (in Russian).
Nõmmik, A. 2003. Eesti Õhutransport geograafia uurimisobjektina: Master's thesis. University of Tartu, Tartu, Estonia (in Estonian).

O'Kelly, M. E. 1983. Multipurpose shopping trips and the size of retail facilities, Annals of the Association of American Geographer 73(2): 231-239. http://dx.doi.org/10.1111/j.1467-8306.1983.tb01410.x

Paas, T. 2000. Gravity approach for modeling trade flows between Estonia and the main trading partners. University of Tartu, Working Paper Series 4(1) [online], [cited 30 May 2015]. Available from Internet: http://www.mtk.ut.ee/ sites/ default/files/mtk/toimetised/febawb4.pdf

Russel, B. 1994. The greatness of Albert Einstein, in M. Gardner (Ed.). Great Essays in Science. New York: Prometheus Books, 408-412.

Rodriguez, J. P.; Comtois, C.; Slack, B. 2009. The geography of transport systems. New York: Routledge.

Srinidhi, S. 2010. Demand model for air passenger traffic on international sectors, South Asian Journal of Management 17(3): 53-70.

Tallinn Airport. 2015. Traffic report 2015.

Tallinn Airport Timetable. 2014. [online], [cited 20 October 2014]. Available from Internet: http://www.tallinn-airport.ee/eng/info/timetable

Tibbetts, P. 1982. The positivism-humanism debate in sociology: a reconsideration, Sociological Inquiry 52(3): 184-199. http://dx.doi.org/10.1111/j.1475-682X.1982.tb01249.x

Truscott, J.; Ferguson, N. M. 2012. Evaluating the adequacy of gravity models as a description of human mobility for epidemic modelling, PLOS Computational Biology 8(10): 1-12. http://dx.doi.org/10.1371/journal.pcbi.1002699

Weber, J. S; Sen, A. K. 1985. On the sensitivity of gravity model forecasts, Journal of Regional Science 25(3): 317-336. http://dx.doi.org/10.1111/j.1467-9787.1985.tb00303.x 